\title{
Onderzoek
}

\begin{tabular}{ll}
\hline Uitgave & Huisarts en Wetenschap \\
ISBN & $0018-7070$ \\
BSL-id & \\
Uitgave type & tijdschrift \\
Subuitgave titel & Huisarts en Wetenschap, jaargang 2018, nummer 4 \\
Volumenummer & 61 \\
Issuenummer & 4 \\
Copyright & onbekend \\
Datum & 2018 \\
Eerste pagina & \\
Laatste pagina &
\end{tabular}

\section{CRP-test alleen bij acuut zieke kinderen met hoger risico}

Jan Verbakel, Marieke Lemiengre, Tine de Burghgraeve, An de Sutter, Bert Aertgeerts, Bethany Shinkins, Rafael Perera, David Mant, Ann van den Bruel en Frank Buntinx ${ }^{l}$

Inleiding Een CRP-sneltest via een vingerprik zou de huisarts kunnen helpen bij het uitsluiten van een ernstige infectie bij kinderen. Wij hebben onderzocht of we de sneltest bij alle kinderen moeten aanbieden of alleen bij kinderen met klinische risicofactoren.

Methode We hebben een clustergerandomiseerd onderzoek uitgevoerd onder acuut zieke kinderen die zich aanmeldden bij 133 huisartsen in 78 huisartspraktijken in België (3147 ziekte-episodes). We hebben praktijken gerandomiseerd om een CRP-sneltest uit te voeren bij alle kinderen of alleen bij kinderen met klinische risicofactoren (kortademigheid, temperatuur $\geq 40{ }^{\circ} \mathrm{C}$, diarree bij kinderen tussen 12 tot 30 maanden of een niet-pluisgevoel van de arts). De uitkomstmaat was ziekenhuisopname met een ernstige infectie binnen 5 dagen.

Resultaten Als kinderen een CRP-test krijgen op basis van klinische risicofactoren, is zo'n test slechts nodig bij $20 \%$ van de kinderen. Er was tussen de twee onderzoeksgroepen geen verschil in het aantal kinderen met een ernstige infectie dat de huisartsen dadelijk naar het ziekenhuis verwezen $(0,16 \%$ versus $0,14 \%, p=0,88)$, of misten bij het eerste contact $(0,29 \%$ versus $0,14 \%, p=0,35)$. Elf kinderen hadden een ernstige infectie, van hen hadden er 6 een CRP van minder dan $20 \mathrm{mg} / \mathrm{L}$. Slechts één kind met een CRP < $5 \mathrm{mg} / \mathrm{L}$ had een ziekte die een opname rechtvaardigde.

Conclusie De CRP-sneltest is alleen nuttig bij kinderen met klinische risicofactoren. Een CRP < 5 mg/L sluit een ernstige infectie uit en kan de huisarts helpen om onnodige verwijzingen te vermijden. Het klinische oordeel van de arts blijft essentieel, zelfs als een lage CRP-waarde een ernstige infectie lijkt uit te sluiten.

\footnotetext{
${ }^{1}$ Verbakel JY, Lemiengre MB, De Burghgraeve T, De Sutter A, Aertgeerts B, Shinkins B, Perera R, Mant D, Van den Bruel A, Buntinx F. CRP-test alleen bij acuut zieke kinderen met hoger risico. Huisarts Wet 2018;61(4):DOI: Nuffield Department of Primary Care Health Sciences, University of Oxford, Oxford, Verenigd Koninkrijk: J.Y. Verbakel, docent Huisartsgeneeskunde; R. Perera, professor of Statistics; D. Mant, professor of Primary Care; A. van den Bruel, hoofddocent Huisartsgeneeskunde. Departement Maatschappelijke Gezondheidszorg en Eerstelijnszorg, KU Leuven, Leuven, België: J.Y. Verbakel, docent Huisartsgeneeskunde; T. de Burghgraeve, postdoctoraal onderzoeker; B. Aertgeerts, hoogleraar Huisartsgeneeskunde; F. Buntinx, hoogleraar Huisartsgeneeskunde. Vakgroep Huisartsgeneeskunde en Eerstelijnszorg, Universiteit Gent, Gent, België: M.B. Lemiengre, doctoraatsstudent; A. de Sutter, hoogleraar Huisartsgeneeskunde. Leeds Institute of Health Sciences, University of Leeds, Leeds, Verenigd Koninkrijk: B. Shinkins, lecturer. Care and Public Health Research Institute Caphri, Maastricht University, Maastricht: F. Buntinx, hoogleraar Huisartsgeneeskunde.

Correspondentie: jan.verbakel@phc.ox.ac.uk

Mogelijke belangenverstrengeling: niets aangegeven.

Dit artikel is een bewerking en vertaling van Verbakel JY, Lemiengre MB, De Burghgraeve T, De Sutter A, Aertgeerts B, Shinkins B, Perera R, Mant D, Van den Bruel A, Buntinx F. Should all acutely ill children in primary care be tested with point-of-care CRP: a cluster randomised trial. BMC Med 2016;14:131.
} 


\section{Wat is bekend?}

- Vroegtijdige herkenning van ernstige infecties bij kinderen in de eerste lijn is cruciaal om complicaties en sterfte te vermijden.

- $\quad$ Een CRP-sneltest kan nuttig zijn in de eerste lijn.

\section{Wat is nieuw?}

- $\quad$ De CRP-sneltest is alleen nuttig bij kinderen met klinische risicofactoren.

- $\quad$ CRP $<5 \mathrm{mg} / \mathrm{L}$ sluit een ernstige infectie uit, maar het klinisch oordeel van de arts blijft belangrijk.

\section{Inleiding}

Acute infectie is een van de meest voorkomende ziektebeelden bij kinderen in de eerste lijn. Ernstige infecties zijn zeldzaam (< $1 \%$ van de acuut zieke kinderen bij de huisarts). 1 Longontsteking komt het meest voor, gevolgd door urineweginfecties en (zelden) sepsis, meningitis of osteomyelitis.2-4 Vroegtijdige herkenning is belangrijk om complicaties en overlijden te voorkomen, maar wordt bemoeilijkt door het aspecifieke beeld. $\underline{\underline{5}}$ Voor de eerste lijn is er slechts één klinische beslisregel, die een sensitiviteit van $100 \%$ en een specificiteit van $81 \%$ heeft. $\underline{\underline{4}}$ Hiermee kan je bij de meeste kinderen een ernstige infectie uitsluiten, maar $20 \%$ van de kinderen krijgt dan een ernstige infectie toegemeten.

Betere diagnostische hulpmiddelen kunnen de aanpak van acuut zieke kinderen in de eerste lijn versterken. Ontstekingsparameters, zoals C-reactief proteïne (CRP) en procalcitonine, hebben hun nut bewezen in het ziekenhuis. $\underline{\underline{6}}$ Een CRP-sneltest kan ook interessant zijn voor de huisarts. $\underline{\underline{7,8}}$

We hebben gekeken of huisartsen de sneltest bij alle kinderen moeten aanbieden of alleen bij kinderen met een hoger risico na klinische evaluatie. Daarnaast bekeken we hoe we de CRP-resultaten moeten interpreteren - kan een lage CRP-waarde een ernstige infectie uitsluiten en een verwijzing naar het ziekenhuis voorkomen?

\section{Methode}

We hebben een clustergerandomiseerd onderzoek uitgevoerd bij kinderen van 1 maand tot 16 jaar die zich aanmeldden met een ziekte-episode (maximaal 5 dagen) bij 133 huisartsen in 78 huisartspraktijken in België. Kinderen met een ziekte ten gevolge van een trauma of een neurologische aandoening, intoxicatie, een psychiatrisch probleem of verergering van een bekende chronische aandoening kwamen niet in aanmerking.

We hebben praktijken gerandomiseerd om ofwel een CRP-sneltest (Afinion ${ }^{\mathrm{TM}}$ CRP Test via vingerprik, met een meetbereik van 5-200 mg/L en resultaat binnen 4 minuten) $\underline{8}$ uit te voeren bij alle kinderen (1730 ziekte-episodes) of alleen bij kinderen met een hoger risico op een ernstige infectie op basis van de eerdergenoemde beslisregel (1417 ziekte-episodes). Deze is positief bij aanwezigheid van een van de volgende aanwijzingen: kortademigheid, temperatuur $\geq 40{ }^{\circ} \mathrm{C}$, diarree bij een kind tussen 12 en 30 maanden of een niet-pluisgevoel van de arts. 2

De uitkomstmaat was ziekenhuisopname voor een ernstige infectie binnen 5 dagen. Ernstige infecties zijn sepsis, meningitis, appendicitis, pneumonie, osteomyelitis, bacteriële gastro-enteritis of een complicatie bij een urineweginfectie.

We gingen na of het kind in het ziekenhuis terechtkwam door informatie in te winnen bij alle relevante ziekenhuizen en huisartsen, en bij de ouders via een dagboekje na het consult.

Secundaire uitkomstmaten waren verwijzing (onmiddellijk of uitgesteld) naar de tweede lijn en aanvraag van aanvullende onderzoeken (zoals bloed- of urinetests, beeldvorming) door de behandelende huisarts.

De huisartsen kregen geen instructies om de CRP-waarden te interpreteren. $\underline{\underline{6}}$

Met een mixed-effect logistische regressieanalyse hebben we herschil onderzocht in aantal tijdige diagnoses, verwijzingen naar het ziekenhuis en aanvullende onderzoeken tussen de interventiegroepen, rekening houdend met de clustering op praktijkniveau en andere interactietermen, zoals de leeftijd van het kind. De analyses hebben we uitgevoerd in Stata software (versie 11.2; Stata Corp., VS) en JMP Statistical Discovery (versie Pro 12.1.0; SAS Institute Inc., VS).

\section{Resultaten}

Tussen 15 februari 2013 en 28 februari 2014 hebben we 3147 ziekte-episodes geïncludeerd bij 2773 kinderen. De mediane leeftijd van de kinderen was 3,2 jaar (interkwartielspreiding 1,5-6,9) en 1659 waren jongens $(52,7 \%)$. Tabel 1 laat zien dat de twee groepen goed in evenwicht waren qua geslacht en aanmeldingsklachten, hoewel er 
een klein verschil was in leeftijd. De huisartsen stelden 11 ernstige infecties vast, 4 in de beperkte CRP-groep en 7 in de 'CRP bij iedereen'-groep.

$\underline{\text { Tabel }} \underline{1}$ Kenmerken van de kinderen bij aanmelding voor iedere randomisatie-arm

\begin{tabular}{|c|c|c|c|c|c|}
\hline & \multicolumn{2}{|c|}{$\begin{array}{l}\text { CRP bij } \\
\text { kinderen } \\
(n=1730)\end{array}$} & \multicolumn{2}{|c|}{$\begin{array}{l}\mathrm{CRP} \text { alleen bij } \\
\text { kinderen met hoger } \\
\text { risico } \\
(\mathrm{n}=1417)\end{array}$} & \multirow[t]{2}{*}{ p-waarde } \\
\hline & $\mathrm{n}$ & $\%$ of IQR & $\mathrm{n}$ & $\%$ of IQR & \\
\hline Jongen & 942 & $53,4 \%$ & 735 & $51,9 \%$ & 0,36 \\
\hline Leeftijd (mediaan) & 3,6 & $1,6-8$ & 2,7 & $1,3-5,5$ & $<0,0001$ \\
\hline Koorts $\geq 38^{\circ} \mathrm{C}$ & 961 & $85,7 \%$ & 949 & $87,6 \%$ & 0,19 \\
\hline Duur van de koorts & 2 & $1-2$ & 2 & $1-2$ & 0,99 \\
\hline Diarree of braken & 409 & $24,2 \%$ & 347 & $25,0 \%$ & 0,61 \\
\hline Kortademigheid & 99 & $6,0 \%$ & 65 & $4,7 \%$ & 0,13 \\
\hline Lichaamstemperatuur $\geq 40^{\circ} \mathrm{C}$ & 119 & $7,6 \%$ & 120 & $9,5 \%$ & 0,09 \\
\hline Diarree en 12-30 maanden & 75 & $4,4 \%$ & 77 & $5,6 \%$ & 0,15 \\
\hline Niet-pluisgevoel & 192 & $11,6 \%$ & 148 & $10,8 \%$ & 0,48 \\
\hline
\end{tabular}

CRP: CRP-sneltest; IQR: interkwartielspreiding

\section{Impact van de teststrategie op de klinische aanpak}

Tabel 2 laat zien dat het beperken van de CRP-sneltest tot kinderen met een hoger risico (op basis van kortademigheid, temperatuur $\geq 40^{\circ} \mathrm{C}$, diarree en leeftijd 12 tot 30 maanden of een niet-pluisgevoel) het aantal te testen kinderen substantieel vermindert naar 20,1\% (95\%-BI 18,0 tot 22,2\%). Met deze strategie krijgen alle kinderen met een ernstige infectie een CRP-test. Hoewel in de beperkte CRP-arm minder kinderen een verwijzing kregen $(2,1 \%$ versus $2,9 \%)$, was het verschil niet statistisch significant $(\mathrm{p}=0,15)$. Het aantal kinderen met een ernstige infectie $(0,28 \%$ versus $0,40 \%)$, onmiddellijke verwijzing naar het ziekenhuis $(0,14 \%$ versus $0,16 \%)$ en een laattijdige opname in het ziekenhuis $(0,14 \%$ versus $0,29 \%, \mathrm{p}=0,35)$ was ook niet significant lager in de beperkte CRP-arm.

Tabel 2 Klinische aanpak en uitkomstmaat per randomisatie-arm

\begin{tabular}{|c|c|c|c|c|c|c|}
\hline & \multicolumn{2}{|c|}{$\begin{array}{l}\text { CRP bij alle } \\
\text { kinderen } \\
(\mathrm{n}=1730)\end{array}$} & \multicolumn{2}{|c|}{$\begin{array}{l}\text { CRP enkel bij } \\
\text { kinderen met hoger } \\
\text { risico }(n=1417)\end{array}$} & \multicolumn{2}{|c|}{$\begin{array}{l}\text { Oddsratio gecorrigeerd } \\
\text { voor leeftijd en } \\
\text { clustering }\end{array}$} \\
\hline & $\mathrm{n}$ & $\%$ & $\mathrm{n}$ & $\%$ & GOR & $(95 \%-B I)$ \\
\hline CRP-sneltest & 1730 & $100 \%$ & 285 & $20,1 \%$ & - & \\
\hline Verwezen naar ziekenhuis & 50 & $2,9 \%$ & 30 & $2,1 \%$ & 0,61 & $(0,31-1,21)$ \\
\hline Ernstige infectie & 7 & $0,40 \%$ & 4 & $0,28 \%$ & 0,61 & $(0,15-2,39)$ \\
\hline Zonder CRP-sneltest & 0 & 0 & 0 & 0 & - & \\
\hline Dadelijk verwezen & 2 & $0,16 \%$ & 2 & $0,14 \%$ & 1,16 & $(0,16-8,41)$ \\
\hline Laattijdig verwezen & 5 & $0,29 \%$ & 2 & $0,14 \%$ & 0,43 & $(0,07-2,53)$ \\
\hline
\end{tabular}

GOR: gecorrigeerde oddsratio's; CRP: CRP-sneltest; 95\%-BI: 95\%-betrouwbaarheidsinterval

\section{Diagnostische waarde van de CRP-sneltest}

De impact op de diagnostische waarde van de CRP-sneltest is weergegeven in tabel 3. Het lage aantal ernstige infecties resulteert in brede betrouwbaarheidsintervallen, zonder duidelijk verschil tussen de randomisatiegroepen. Bij een afkapwaarde van $5 \mathrm{mg} / \mathrm{L}$ misten de huisartsen geen enkele ernstige infectie. Het aantal vals alarmen was 
vergelijkbaar in beide groepen, onafhankelijk van de gekozen afkapwaarde. Als de huisartsen $5 \mathrm{mg} / \mathrm{L}$ als enige criterium zouden gebruiken voor verwijzing naar het ziekenhuis, zou meer dan de helft $(59,2 \%)$ van de kinderen een verwijzing hebben gekregen. Van deze kinderen had slechts 1 op 40 in de beperkte CRP-arm een ernstige infectie (positief voorspellende waarde: $2,4 \%$ ). Indien de huisartsen alle kinderen zouden testen en degene met een $\mathrm{CRP} \geq 5 \mathrm{mg} / \mathrm{L}$ zouden verwijzen, dan zou de positief voorspellende waarde zelfs nog lager zijn $(0,8 \%)$, waarbij slechts 1 op 130 kinderen een ernstige infectie zou hebben (figuur 1).

Tabel 3Diagnostische waarde van CRP voor een ernstige infectie bij verschillende afkapwaarden per randomisatiegroep

\begin{tabular}{cllllll}
\hline & \multicolumn{2}{l}{ CRP bij alle kinderen } & \multicolumn{3}{l}{ CRP alleen bij kinderen met hoger risico } \\
\hline Gemiste diagnoses & $\mathrm{n} / \mathrm{N}$ & $\%$ & $95 \%-\mathrm{BI}$ & $\mathrm{n} / \mathrm{N}$ & $\%$ & $95 \%-\mathrm{BI}$ \\
$\geq 5 \mathrm{mg} / \mathrm{L}$ & $0 / 7$ & 0 & $0,0-40,9$ & $0 / 4$ & 0 & $0,0-60,2$ \\
$\geq 20 \mathrm{mg} / \mathrm{L}$ & $3 / 7$ & 42,9 & $9,9-81,6$ & $3 / 4$ & 75 & $19,4-99,4$ \\
$\geq 80 \mathrm{mg} / \mathrm{L}$ & $6 / 7$ & 85,7 & $42,1-99,6$ & $4 / 4$ & 100 & $39,7-100$ \\
$\geq 200 \mathrm{mg} / \mathrm{L}$ & $6 / 7$ & 85,7 & $42,1-99,6$ & $4 / 4$ & 100 & $39,7-100$ \\
& & & & & & \\
Vals alarm & $\mathrm{n} / \mathrm{N}$ & $\%$ & $95 \%-\mathrm{BI}$ & $\mathrm{n} / \mathrm{N}$ & $\%$ & $95 \%-\mathrm{BI}$ \\
$\geq 5 \mathrm{mg} / \mathrm{L}$ & $918 / 1723$ & 53,3 & $49,9-56,8$ & $161 / 281$ & 57,3 & $51,3-63,2$ \\
$\geq 20 \mathrm{mg} / \mathrm{L}$ & $448 / 1723$ & 26,0 & $23,9-28,1$ & $85 / 281$ & 30,2 & $24,9-36,0$ \\
$\geq 80 \mathrm{mg} / \mathrm{L}$ & $65 / 1723$ & 3,8 & $2,9-4,8$ & $14 / 281$ & 5,0 & $2,8-8,2$ \\
$\geq 200 \mathrm{mg} / \mathrm{L}$ & $2 / 1723$ & 0,1 & $0,0-0,4$ & $2 / 281$ & 0,7 & $0,0-2,5$ \\
& & & & & &
\end{tabular}

CRP: CRP-sneltest; 95\%-BI: 95\%-betrouwbaarheidsinterval



Figuur 1Diagnostische waarde van CRP om een ernstige infectie uit te sluiten

Om 1 kind met een ernstige infectie te detecteren, zou de beslisboom 57 kinderen aanduiden als hoog risico. Een CRPsneltest kan een ernstige infectie uitsluiten bij 22 extra kinderen, waardoor minder kinderen een verwijzing krijgen of aanvullende onderzoeken hoeven te ondergaan.

\section{Doorverwezen kinderen met een normale CRP-waarde}

Vierentwintig kinderen kregen een verwijzing naar het ziekenhuis met een lage CRP-waarde $(<5 \mathrm{mg} / \mathrm{L})$, bij 17 van hen $(70,8 \%)$ om een ernstige infectie uit te sluiten. Slechts één kind werd opgenomen, vanwege dehydratie.

\section{Beschouwing}

Het is niet efficiënt om bij alle zieke kinderen een CRP-sneltest uit te voeren. De diagnostische waarde van de CRP-sneltest is hoger als men de test alleen uitvoert bij kinderen met ten minste één risicofactor van een klinische beslisregel. Er is een lage drempel nodig om ernstige infecties uit te sluiten, namelijk minder dan $5 \mathrm{mg} / \mathrm{L}$. Op basis van ons onderzoek lijkt het veilig om kinderen met een dergelijk lage CRP-waarde niet te verwijzen naar het ziekenhuis. Door de klinische beslisregel en CRP-sneltest op zo'n stapsgewijze manier toe te passen, zal de huisarts een ernstige infectie bij 90\% van de acuut zieke kinderen kunnen uitsluiten. Bij de resterende 10\% (positief op de klinische beslisregel en met een CRP $\geq 5 \mathrm{mg} / \mathrm{L}$ ) zal 1 op 40 kinderen een ernstige infectie hebben, wat aanmerkelijk hoger is dan het basisrisico van 1 op 300, maar mogelijk toch nog verdere verfijning behoeft.

Dit onderzoek vond plaats in een groot aantal praktijken, met 133 huisartsen, en omvat 3147 ziekte-episodes. We hebben gebruikgemaakt van robuuste methoden voor randomisatie en uitkomstbeoordeling, hoewel blindering niet mogelijk is in clustergerandomiseerde onderzoeken.

De artsen kregen geen instructies om de CRP-waarden te interpreteren, aangezien er op dat moment nog geen adviezen beschikbaar waren voor kinderen die bij de huisarts op het spreekuur kwamen. Dit kan het gebrek aan significante effecten van de CRP-sneltest op aanvullende onderzoeken en verwijzingen verklaren. Eerdere 
onderzoeken over het effect van CRP op antibioticavoorschrijfgedrag bij volwassenen toonden aan dat dit advies van cruciaal belang was om het gedrag te beïnvloeden. $\underline{\underline{9}}$

Het onderzoek omvatte geen groep zonder CRP-sneltest en we hebben de klinische evaluatie van alle kinderen gebaseerd op een gevalideerde beslisregel. Daardoor konden we geen vergelijking maken met gebruikelijke zorg. Een systematische review van onderzoeken in het ziekenhuis suggereert dat een CRP $<20 \mathrm{mg} / \mathrm{L}$ het meest geschikt is om ernstige infecties bij kinderen uit te sluiten. $\underline{6} \mathrm{Wij}$ vonden een lagere afkapwaarde in ons onderzoek $(5 \mathrm{mg} / \mathrm{L})$, waarschijnlijk omdat kinderen zich eerder in het ziekteproces bij de huisarts meldden en de CRP-waarde nog niet de tijd had gekregen om sterk te stijgen. $\underline{\underline{10}}$

De meeste onderzoeken naar het gebruik van CRP door de huisarts richten zich op antibioticavoorschrijfgedrag bij volwassenen. Een Cochrane-review suggereert dat artsen tot $30 \%$ minder antibiotica voorschrijven als ze een CRP-test uitvoeren bij volwassenen met aanwijzingen voor een lageluchtweginfectie. $\underline{9}$

Gegevens van een multinationale RCT bij volwassenen suggereerde dat CRP de diagnostische onzekerheid bij de huisarts kan verminderen en patiënten kan geruststellen.11 Het toevoegen van CRP > $30 \mathrm{mg} / \mathrm{L}$ verbetert de diagnostische accuraatheid van een beslisregel voor pneumonie bij patiënten met acute hoest. 12 Als huisartsen een vergelijkbare drempel van $20 \mathrm{mg} / \mathrm{L}$ bij kinderen zouden toepassen, zouden ze $40 \%$ van de ernstige infecties missen. We hebben ook het effect van CRP bij kinderen op het antibioticavoorschrijfgedrag van huisartsen onderzocht, vergeleken met een communicatiestrategie. Deze resultaten zullen we later apart publiceren.

In de dagelijkse praktijk blijft het klinisch oordeel van de huisarts essentieel, vooral wanneer er nog sprake is van diagnostische onzekerheid. Correcte vangnetprocedures (zoals herevaluatie, telefonische opvolging, uitleggen van alarmsignalen) 13,14 zijn hierbij van groot belang. Verder onderzoek kan zich het beste richten op de implementatie van deze beslisregel met de CRP-sneltest, en de kosten en baten van deze diagnostische strategie. Zoals het implementatieonderzoek van Minnaard et al. bij acute hoest bij volwassenen aantoont blijken huisartsen de aanbevelingen zoals opgesteld in een nationale richtlijn niet te volgen, met het risico tot overconsumptie en foutief gebruik van de CRP-sneltest.15,16 Correcte nascholing en training zijn essentieel om zo daadwerkelijk een impact te hebben op de dagelijkse klinische praktijk.

\section{Conclusie}

De CRP-sneltest is alleen nuttig bij kinderen met kortademigheid, koorts $\geq 40{ }^{\circ} \mathrm{C}$, diarree bij kinderen tussen 12 en 30 maanden of wanneer de huisarts een niet-pluisgevoel heeft. Een CRP $<5 \mathrm{mg} / \mathrm{L}$ sluit dan een ernstige infectie uit. Het klinisch oordeel van de arts blijft essentieel. •

\section{Literatuur}

Van den Bruel A, Bartholomeeusen S, Aertgeerts B, Truyers C, Buntinx F. Serious infections in children: an incidence study in family practice. BMC Fam Pract 2006;7:23.

Van den Bruel A, Aertgeerts B, Bruyninckx R, Aerts M, Buntinx F. Signs and symptoms for diagnosis of serious infections in children: a prospective study in primary care. Br J Gen Pract 2007;57:538-46.

Van den Bruel A, Thompson M. Research into practice: acutely ill children. Br J Gen Pract 2014;64:311-3.

Verbakel JY, Lemiengre MB, De Burghgraeve T, De Sutter A, Aertgeerts B, Bullens DM, et al. Validating a decision tree for serious infection: diagnostic accuracy in acutely ill children in ambulatory care. BMJ Open 2015;5:e008657.

Van den Bruel A, Haj-Hassan T, Thompson M, Buntinx F, Mant D. Diagnostic value of clinical features at presentation to identify serious infection in children in developed countries: a systematic review. Lancet 2010;375:834-45.

Van den Bruel A, Thompson M, Haj-Hassan T, Stevens R, Moll H, Lakhanpaul M, et al. Diagnostic value of laboratory tests in identifying serious infections in febrile children: systematic review. BMJ 2011;342:d3082.

Minnaard MC, Van de Pol AC, Broekhuizen BD, Verheij TJ, Hopstaken RM, Van Delft S, et al. Analytical performance, agreement and user-friendliness of five C-reactive protein point-of-care tests. Scand J Clin Lab Invest 2013;73:627-34.

Verbakel JY, Aertgeerts B, Lemiengre MB, De Sutter A, Bullens DM, Buntinx F. Analytical accuracy and user-friendliness of the Afinion point-of-care CRP test. J Clin Pathol 2014;67:83-6.

Aabenhus R, Jensen JU, Jorgensen KJ, Hrobjartsson A, Bjerrum L. Biomarkers as point-of-care tests to guide prescription of antibiotics in patients with acute respiratory infections in primary care. Cochrane Database Syst Rev 2014;11:CD010130.

Leeflang MM, Rutjes AW, Reitsma JB, Hooft L, Bossuyt PM. Variation of a test's sensitivity and specificity with disease prevalence. CMAJ 2013;185:E537-44.

Anthierens S, Tonkin-Crine S, Cals JW, Coenen S, Yardley L, Brookes-Howell L, et al. Clinicians' views and experiences of interventions to enhance the quality of antibiotic prescribing for acute respiratory tract infections. J Gen Intern Med 2015;30:408-16.

Van Vugt SF, Broekhuizen BD, Lammens C, Zuithoff NP, De Jong PA, Coenen S, et al. Use of serum C reactive protein and procalcitonin concentrations in addition to symptoms and signs to predict pneumonia in patients presenting to primary care with acute cough: diagnostic study. BMJ 2013;346:f2450.

Jones C, Neill S, Lakhanpaul M, Roland D, Singlehurst-Mooney H, Thompson M. The safety netting behaviour of first contact clinicians: a qualitative study. BMC Fam Pract 2013;14:140.

Roland D, Jones C, Neill S, Thompson M, Lakhanpaul M. Safety netting in healthcare settings: what it means, and for whom? Arch Dis Child Educ Pract Ed 2014;99:48-53. 
Minnaard MC, Van de Pol AC, Hopstaken RM, Van Delft S, Broekhuizen BD, Verheij TJ, et al. C-reactive protein point-ofcare testing and associated antibiotic prescribing. Fam Pract 2016;33:408-13.

Verheij T, Hopstaken RM, Prins JM, Salomé PJ, Bindels PJ, Ponsioen BP, et al. NHG-Standaard Acuut hoesten. Huisarts Wet 2011;54:86-92.

streamers

Het is niet efficiënt om bij alle zieke kinderen een CRP-sneltest uit te voeren

Met de klinische beslisregel en CRP-sneltest kan de huisarts een ernstige infectie bij 90\% van de acuut zieke kinderen uitsluiten

Het klinisch oordeel van de arts blijft hoe dan ook essentieel 